\title{
Comparison of Balloon Trocar versus Telescopic Dissection Method for TEP Inguinal Hernia Repair
}

\author{
Emrah Akin ${ }^{1}$, Enes Bas ${ }^{1}$, Necattin Firat ${ }^{2}$, Kayhan Ozdemir ${ }^{1}$, Recayi Capoglu ${ }^{1}$ and Fatih Altintoprak ${ }^{2}$ \\ ${ }^{1}$ Department of General Surgery, Sakarya University Research and Educational Hospital, Sakarya, Turkey \\ ${ }^{2}$ Department of General Surgery, Faculty of Medicine, Sakarya University, Turkey
}

\begin{abstract}
Objective: To compare the outcomes between two methods of dissection (balloon trocar vs. telescopic dissection) used in total extra-peritoneal (TEP) inguinal hernia repair.

Study Design: Comparative study.

Place and Duration of Study: Department of General Surgery, Faculty of Medicine, Sakarya University, conducted between January 2018 and January 2020.

Methodology: The study included patients who underwent elective TEP inguinal hernia repair. Preoperative and early postoperative results were compared, after the patients had been divided into a balloon trocar group (Group 1) and telescopic dissection group (Group 2). The technique performed depended on equipment availability. Permission was obtained from the Institutional Review Board. The study data are presented as descriptive statistics (mean, standard deviation, median, first quartile, third quartile, frequency and percentage); $p$-value $<0.05$ was considered significant.

Results: A total of 189 patients were included; 95 patients in Group 1 and 94 patients in Group 2. No significant differences in age, gender, body mass index, body weight, ASA performance status, operating time, duration of hospitalisation or postoperative bleeding values were observed between the groups $(p>0.05)$. European Hernia Society Quality of Life pain score values were higher in Group 2 than Group $1(p=0.016)$.

Conclusion: Telescopic dissection was cheaper than balloon dissection. The bleeding values and operating time were similar between the two methods, but telescopic dissection caused more postoperative pain.
\end{abstract}

Key Words: Inguinal hernia, Telescopic dissection, Balloon dissection, Total extra-peritoneal (TEP) surgery.

How to cite this article: Akin E, Bas E, Firat N, Ozdemir K, Capoglu R, Altintoprak F. Comparison of Balloon Trocar versus Telescopic Dissection Method for TEP Inguinal Hernia Repair. J Coll Physicians Surg Pak 2021; 31(06):623-626.

\section{INTRODUCTION}

Totally extraperitoneal (TEP) surgery was first used in the early 1990s for treating inguinal hernias. ${ }^{1}$ The initial step of TEP surgery was dissection of the spaces of Bogros and Retzius, to create a preperitoneal space. ${ }^{2}$ The balloon trocar method was introduced in 1994 and has been used to create a preperitoneal working area. ${ }^{3}$ The telescopic dissection technique, first described in 2001, can create a preperitoneal working area directly with the help of a telescope, without using balloon trocar. ${ }^{4}$

The International Hernia Association recommends balloon dissection at the A level of evidence, particularly for inexperienced surgeons. ${ }^{5}$ Balloons have been reported to provide faster, less bloody, and more uniform surgery. ${ }^{6,7}$

Correspondence to: Dr. Emrah Akin, Department of General Surgery, Sakarya University Research and Educational Hospital, Sakarya, Turkey

E-mail: emrahakin@sakarya.edu.tr

Received: February 14, 2021; Revised: May 07, 2021; Accepted: May 24, 2021

DOI: https://doi.org/10.29271/jcpsp.2021.06.623
However, due to the increase in experience of using TEP and implementation of training programmes, the technique has been applied worldwide, and costs have been accurately determined. The use of balloon trocar during dissection increases the cost of surgery by $\$ 350-600$. This time-consuming manoeuvre can cause bleeding due to dissection and does not preserve anatomical structures. Moreover, the balloon itself, or the bladder, may rupture. ${ }^{8}$ Therefore, the necessity of using a trocar beenquestioned.

The aim of this study was to compare the outcomes of using balloon trocar and telescopic methods to create a preperitoneal working area during TEP.

\section{METHODOLOGY}

Records of TEP surgeries performed under elective conditions at the Department of General Surgery, Faculty of Medicine, Sakarya University between January 2018 and January 2020 in patients with a diagnosis of inguinal hernia, were evaluated retrospectively. This study was approved by the Faculty of Medicine, Sakarya University Ethics Committee (No. 71522473/050.01.04/308; date: 21.05.2020). Patients with incarcerated, strangulated, recurrent or scrotal hernias, those 
operated on under emergency conditions, and those with a history of lower abdominal surgery, coagulopathy, anticoagulant use and/or immunosuppressive therapy, were excluded from the study.

The patients' demographic characteristics, body mass index (BMI), American Society of Anaesthesiologists (ASA) status, hernia side, operating time, 7-day European Hernia Society Quality of Life (EuraHS QoL) pain score (range: 0-90 [pain domain, 0-30; restricted activity domain, 0-40; cosmetic domain 0-20]), duration of hospitalisation (days), and postoperative bleeding volume, were obtained by retrospective analysis of Hospital records.

The technique performed depended on equipment availability. Permission from the Institutional Review Board was obtained. Patients, who underwent TEP surgery between January 2018 and January 2020, were divided into Group 1 (operated on using balloon trocar) and Group 2 (operated on using the telescopic dissection method). All operations were performed by the same surgical team, or with their support.

The rectus fascia was opened with a lateralised sub-umbilical incision, and the Space Maker ${ }^{\mathrm{TM}}$ (Medtronic Inc., New Haven, CT, USA) was used for the dissection together with a balloon. The balloon was advanced up to the symphysis pubis. The balloon trocar was pumped 20-25 times and the procedure was repeated thrice to create a preperitoneal dissection area.

Direct vision was achieved by entering with a $52-\mathrm{cm} / 30 \% / 10$ $\mathrm{mm}$ laparoscope through a 10-12 $\mathrm{mm}$ blunt type trocar placed in the preperitoneal space. After dissecting, the craniocaudal axis up to the symphysis pubis, the dissection was extended to the level of spina iliac anterior superior laterally and the linea alba level medially.

Wide dissection of the myopectineal opening was achieved by administering $12 \mathrm{mmHg} \mathrm{CO}$ from a $10-12 \mathrm{~mm}$ trocar and then placing two 5-mm trocars in the midline of the extraperitoneal space under direct vision. Polypropylene mesh $(10 \times 15 \mathrm{~cm})$ was used in all patients. The mesh was fixed at Cooper's ligament in the medial and posterior aspects of the transverse abdominis aponeurosis with absorbable fixators. The operation was continued under direct vision to the other side in bilateral patients, and the same procedures were performed on that side. The postoperative bleeding volume was recorded in all patients by placing a drain through the $5-\mathrm{mm}$ trocar adjacent to the pubis. The EuraHS QoL score was obtained by a telephone interview with the patients.

The Number Cruncher Statistical System 2007 programme (NCSS, Kaysville, UT, USA) was used for the statistical analysis. The data are presented as descriptive statistics (mean, standard deviation, median, first quartile, third quartile, frequency and percentage). The normality of the quantitative data was tested with the Shapiro-Wilk test. The independent-samples ttest was used to compare normally distributed quantitative variables between the two groups. The Mann-Whitney U-test was used for intergroup comparisons of quantitative variables that were not normally distributed. Pearson Chi-square test, Fisher's Exact test and the Fisher-Freeman-Halton Exact tests were used to compare the qualitative data. A p-value $<0.05$ was considered significant.

\section{RESULTS}

A total of 189 patients were included in the study; 95 patients in Group 1 and 94 patients in Group 2 (Table I). The patients' mean age was $46.44 \pm 13.43$ years in Group 1 and $51.50 \pm 14.43$ years in Group 2. There were 93 (97.9\%) male patients in Group 1 and $91(96.8 \%)$ in Group 2. The BMI was $26.34 \pm 2.14 \mathrm{~kg} / \mathrm{m}^{2}$, and $26.77 \pm 2.86 \mathrm{~kg} / \mathrm{m}^{2}$ in Groups 1 and 2, respectively. In total, 65 patients (68.4\%) in Group 1 had an ASA score of 2, compared to 63 patients (67\%) in Group 2. There were $83(87.4 \%)$ patients in Group 1 with unilateral hernias and 74 (78.7\%) in Group 2. The mean operating time was $82.44 \pm 19.32$ min for Group 1 and $87.16 \pm 24.81 \mathrm{~min}$ for Group 2. All patients were hospitalized for 2 days. The average postoperative bleeding volume was 15 (range: 10-25) ml in Group 1 and 20 (range: 10-40) ml in Group2.

Table I: Results of the groups.

\begin{tabular}{|c|c|c|c|}
\hline & Group $1(n=95)$ & Group $2(n=94)$ & $\mathbf{p}$ \\
\hline $\begin{array}{l}\text { Age, mean } \pm \\
\text { sd/year }\end{array}$ & $46.44 \pm 13.43$ & $51.50 \pm 14.43$ & ${ }^{\mathrm{a}} 0.091$ \\
\hline \multicolumn{3}{|l|}{ Gender } & ${ }^{\mathrm{bb}} 0.361$ \\
\hline Male & $93(97.9$ & $91(96.8)$ & \\
\hline Female & $2(2.1$ & $3(3.2)$ & \\
\hline $\mathrm{BMI}$, mean $\pm \mathrm{sd}$ & $26.34 \pm 2.14$ & $26.77 \pm 2.86$ & ${ }^{\mathrm{a}} 0.419$ \\
\hline $\begin{array}{l}\text { Heigh, mean } \pm \\
\text { sd/cm }\end{array}$ & $175.89 \pm 4.90$ & $173.25 \pm 5.40$ & a $0.018 *$ \\
\hline $\begin{array}{l}\text { Weight, mean } \pm \\
\mathrm{sd} / \mathrm{kg}\end{array}$ & $81.31 \pm 5.16$ & $80.23 \pm 7.92$ & ${ }^{\mathrm{a}} 0.445$ \\
\hline \multicolumn{3}{|l|}{ Hernia side } & ${ }^{\mathrm{b}} 0.355$ \\
\hline Unilateral & $83(87.4$ & $74(78.7)$ & \\
\hline Right & $38(40)$ & $40(42.5)$ & \\
\hline Left & $45(47.4$ & $34(36.2$ & \\
\hline Bilateral & $12(12.6)$ & $20(21.3$ & \\
\hline \multicolumn{3}{|l|}{ ASA } & ${ }^{c} 0.909$ \\
\hline 1 & $28(29.5$ & $29(30.9)$ & \\
\hline 2 & $65(68.4)$ & $63(67)$ & \\
\hline 3 & $2(2.1)$ & $2(2.1)$ & \\
\hline $\begin{array}{l}\text { Duration of } \\
\text { surgery, mean } \pm \\
\text { sd/min }\end{array}$ & $82.44 \pm 19.32$ & $87.16 \pm 24.81$ & ${ }^{\mathrm{a}} 0.319$ \\
\hline Unilateral & $66.32 \pm 12.76$ & $64.26 \pm 32.08$ & ${ }^{\mathrm{a}} 0.117$ \\
\hline Bilateral & $93.42 \pm 10.46$ & $91.34 \pm 18.16$ & ${ }^{\mathrm{a}} 0.231$ \\
\hline $\begin{array}{l}\text { Hospitalisation } \\
\text { day, median (Q1, } \\
\text { Q3)/day }\end{array}$ & $2(2,2)$ & $2(2,2)$ & ${ }^{d} 0.763$ \\
\hline $\begin{array}{l}\text { Postoperative } \\
\text { bleeding volume, } \\
\text { median (Q1, } \\
\text { Q3)/cc }\end{array}$ & $15(10,25)$ & $20(10,40)$ & ${ }^{d} 0.492$ \\
\hline $\begin{array}{l}\text { EuraHS Pain } \\
\text { Score, mean } \pm \text { sd }\end{array}$ & $20.11 \pm 8.71$ & $24.14 \pm 6.55$ & ${ }^{\mathrm{a}} 0.016$ \\
\hline \multicolumn{4}{|c|}{$\begin{array}{l}\text { Independent samples } t \text { test }{ }^{b} \text { Pearson Chi-square test }{ }^{b b} \text { Fisher's Exact test } \\
{ }^{c} \text { Fisher-Freeman-Halton Exact test }{ }^{d} \text { Mann-Whitney } U \text { test } \\
\text { Q1: First quartile, Q3: Third quartile. }{ }^{*} p<0.05\end{array}$} \\
\hline
\end{tabular}

No significant differences in age, gender, BMI, weight, ASA status, operating time, duration of hospitalisation or postoperative bleeding volume were observed between the groups ( $p$ 
$>0.05)$. Group 2 cases had a shorter operating time than Group 1 cases $(p=0.018)$. The EuraHS QoL pain score was $20.11 \pm$ 8.71 in Group 1 and $24.14 \pm 6.55$ in Group $2(p=0.016)$.

\section{DISCUSSION}

The TEP technique for laparoscopic inguinal hernia surgery has been increasingly used since 1992, when it was first applied, and is now recommended as the first line treatment for inguinal hernias in women, as well as for bilateral inguinal hernias, recurrent hernias and hernias in athletes. ${ }^{9}$ Good knowledge of laparoscopic surgery and abdominal wall anatomy is necessary to perform TEP surgery, along with sufficient experience. ${ }^{10}$ Reaching the correct plane in the preperitoneal space is vital. ${ }^{11}$ Working in the wrong plane makes the operation impossible due to the risk of bleeding and technical difficulties. ${ }^{12}$ Creating preperitoneal space with a balloon dissector reduces the operating time and rate of conversion to open surgery, but was the only alternative for a long time ${ }^{13,14}$ Balloon dissection has disadvantages, such as a risk of injury to the bladder, a long operation time and bleeding. ${ }^{15,16}$ However, the contribution of balloon dissection to operating time remains controversial. ${ }^{17,18}$ The surgical durations were similar between the present study and previous ones.

The cost of the operation varies according to country; the average cost is $\$ 800-1,600$, and the balloon trocar alone accounts for $\$ 350-600$ of this amount. ${ }^{8}$ While the cost of TEP surgery varies between 4,000 and 10,000 among hospitals in Turkey, the price of balloon trocar varies between 850 and 1,500も. In 2001, Bringman et al. compared balloon trocar and Bringmann telescopic dissection for the first time. ${ }^{4}$ According to their multicentre, randomised study, the average operating time was 54 minutes for telescopic dissection and 61 mins for the balloon procedure. The time difference, which was notstatistically significant, was related to the surgeon's experience. When the operation is performed with telescopic dissection, the cost of the procedure decreases because balloon trocar is not used. Moreover, the total cost may be lower due to the shorter operating time. In the present study, the operating times were similarbetween the two groups.

Small vascular structures can coagulate during telescopic dissection. ${ }^{17}$ Postoperative pain is less intense for patients who have undergone the telescopic dissection method because dissecting the extraperitoneal space under direct vision tends to cause less nerve damage, resulting in less postoperative pain. The reduced likelihood of haemorrhaging, postoperative ecchymosis and local pain are benefits of this technique. Misra et al. reported that pain, scrotal oedema and the formation of seroma increased 6 weeks postoperatively after balloon dissection, as did the frequency of epigastric vessel injury due to the balloon. As a result, it was suggested that there would be no need for balloon trocar after telescopic dissection. Krishna et al. reported that the rate of scrotal oedema increased with age for large hernia defects, scrotal hernias, and distal indirect hernia sacs $^{19}$. In that study, the telescopic dissection and balloon dissection techniques were compared. The methods had similar bleeding volumes, but pain was more complained of, in the telescopic dissection group. These data may be related to the learning curve for the telescopic dissection technique. Although telescopic dissection is safe, and recommended by the International Endohernia Society (IEHS) guidelines of 2018, its use is not widespread in some countries (particularly in the USA). ${ }^{9}$ This may be because disposable balloon trocars can easily be purchased and do not significantly increase the cost of the surgery. In addition, lawsuits can be filed due to complications that may arise when a balloon trocar is not used. ${ }^{16}$ However, difficulties in procuring a balloon trocar in many countries, and the significant increase in surgical costs, are obstacles to worldwide adoption of the TEP surgical technique.

The limitations of this study included its retrospective nature, the small number of participants, and the single-centre design. In addition, the operations were performed by the same team, or with the support from the same surgeon, and the groups were homogeneous due to randomisation of the patients.

\section{CONCLUSION}

Balloon dissection may reduce operating costs compared to telescopic dissection, with similar bleeding volumes and operating times; however, it may result in more postoperative pain.

\section{ETHICALAPPROVAL:}

This study was approved by the Hospital's Ethics Committee with the No. 71522473 / 050.01.04 and complied with the 1964 Helsinkideclaration and its later amendments.

\section{PATIENT'S CONCENT:}

Written informed consent was obtained from the patient.

\section{CONFLICT OF INTEREST:}

The authors declare that they have no conflict of interest.

\section{AUTHORS' CONTRIBUTION:}

EA: Study concept and design, acquisition of data, analysis and interpretation of data and drafting of manuscript.

$\mathrm{EB}, \mathrm{NF}, \mathrm{KO}$ : Acquisition of data, analysis and interpretation of data.

RC: Analysis and review.

FA: Study conception, drafting of manuscript, analysis and critical revision of manuscript.

\section{REFERENCES}

1. Ferzli GS, Massad A, Albert P. Extraperitoneal endoscopic inguinal hernia repair. J Laparoendosc Surg. 1992; 2(6):281-6. doi:10.1089//ps.1992.2.281.

2. Palser TR, Swift S, Williams RN, Bowrey DJ, Beckingham IJ. Variation in outcomes and use of laparoscopy in elective inguinal hernia repair. BJS Open 2019; 3(4):466-75. doi:10.1002/bjs5.50158.

3. McKernan Null. Prosthetic Inguinal Hernia Repair Using a Laparoscopic Extraperitoneal Approach. Semin LaparosC Surg. 1994; 1(2):116-22. doi:10.1053/SLAS00100116.

4. Bringman S, Ek A, Haglind E. Is a dissection balloon 
beneficial in totally extraperitoneal endoscopic hernioplasty (TEP)? A randomized prospective multicenter study. Surg Endosc. 2001; 15(3):266-70. doi:10.1007/s004640000367.

5. Bittner R, Montgomery MA, Arregui E. Update of guidelines on laparoscopic (TAPP) and endoscopic (TEP) treatment of inguinal hernia (International Endohernia Society). Surg Endosc. 2015; 29(2):289-321. doi:10.1007/s00464014-3917-8.

6. Lomanto D, Clara ELSta. Total Extraperitoneal (TEP) Approach in Inguinal Hernia Repair: The Old and the New. In: Campanelli G, ed. The Art of Hernia Surgery: A Step-byStep Guide. Springer International Publishing; 2018:327-336. doi:10.1007/978-3-319-72626-7_33.

7. Wijerathne S, Agarwal N, Ramzi A, Liem DH, Tan WB, Lomanto D. Single-port versus conventional laparoscopic total extra-peritoneal inguinal hernia repair: a prospective, randomized, controlled clinical trial. Surg Endosc. 2016; 30(4):1356-63. doi:10.1007/s00464-015-4378-4.

8. Faessen JL, Stoot JHMB, van Vugt R. Safety and efficacy in inguinal hernia repair: a retrospective study comparing TREPP, TEP and Lichtenstein (SETTLE). Hernia J Hernias Abdom Wall Surg. Published online January 5, 2021. doi:10.1007/s10029-020-02361-w.

9. HerniaSurge Group. International guidelines for groin hernia management. Hernia J Hernias Abdom Wall Surg 2018; 22(1):1-165. doi:10.1007/s10029-017-1668-x.

10. Kudsi OY, McCarty JC, Paluvoi N, Mabardy AS. Transition from Laparoscopic Totally Extraperitoneal Inguinal Hernia Repair to Robotic Transabdominal Preperitoneal Inguinal Hernia Repair: A Retrospective Review of a Single Surgeon's Experience. World J Surg. 2017; 41(9):2251-7. doi:10.1007/s00268-017-3998-3.

11. Wakasugi M, Nakahara Y, Hirota MI. Learning curve for single-incision laparoscopic totally extraperitoneal inguinal hernia repair. Asian J Endosc Surg 2019; 12(3):301-5. doi:10.1111/ases.12639.

12. Malik AM. Hernia Surgery and Recent Developments. BoD -
Books on Demand; 2018.

13. Yeo D, Kaushal S, Oo AM, Rao J. Eight-fold path to attain laparoscopic totally extraperitoneal (TEP) hernia repair Nirvana - a standardized technique to reduce the learning curve of surgical residents. Asian J Endosc Surg 2020; 13(3):465-9. doi:10.1111/ases.12744.

14. Köhler G, Kaltenböck R, Pfandner R, Dauser B, Lechner M. Precostal top-down extended totally extraperitoneal ventral hernia plasty (eTEP): simplification of a complex technical approach. Hernia J Hernias Abdom Wall Surg 2020; 24(3):527-35. doi:10.1007/s10029-019-02076-7.

15. Misra MC, Kumar S, Bansal VK. Total extraperitoneal (TEP) mesh repair of inguinal hernia in the developing world: comparison of low-cost indigenous balloon dissection versus direct telescopic dissection: a prospective randomized controlled study. Surg Endosc 2008; 22(9):1947-58. doi:10.1007/s00464-008-9897-9.

16. Zuiki T, Ohki J, Ochi M, Lefor AK. Laparoscopic totally extraperitoneal (TEP) inguinal hernia repair in patients with previous lower abdominal surgery. Surg Endosc. 2018; 32(12):4757-62. doi:10.1007/s00464-018-6223-z.

17. Tran H, Tran K, Turingan I, Zajkowska M, Lam V, Hawthorne W. Single-incision laparoscopic inguinal herniorraphy with telescopic extraperitoneal dissection: technical aspects and potential benefits. Hernia J Hernias Abdom Wall Surg 2015; 19(3):407-16. doi:10.1007/s10029-015-1349-6.

18. Tastaldi L, Bencsath K, Alaedeen D. Telescopic dissection versus balloon dissection for laparoscopic totally extraperitoneal inguinal hernia repair (TEP): A registrybased randomized controlled trial. Hernia J Hernias Abdom Wall Surg. 2019; 23(6):1105-13. doi:10.1007/s10029019-02001-y.

19. Krishna A, Bansal VK, Misra MC, Prajapati O, Kumar S. Totally Extraperitoneal Repair in Inguinal Hernia: More Than a Decade's Experience at a Tertiary Care Hospital. Surg Laparosc Endosc Percutan Tech. 2019; 29(4):247-51. doi:10.1097/SLE.0000000000000682. 